\title{
Setting health priorities in a Swiss canton: what do different methods tell us?
}

Doris Schopper, Alberto Manuel Torres, Joaquin Pereira, Catherine Ammon, Natividad Cuende, Monica Alonso, Ana Baylin, Anne Ronchi, André Rougemont

\begin{abstract}
Study objective-Despite excellent mortality indicators, there is clear evidence that the health status of the population of Geneva could be improved if more attention and resources were devoted to prevention strategies. To identify a set of robust health priorities an original approach was used triangulating results between three methods.

Methods-The study calculated potential years of life lost, disability adjusted years of life lost, and conducted a Delphi survey to gather the opinion of health professionals and the general public.

Main results-Several health conditions were unanimously selected by all three methods as top priorities: cardiovascular diseases, AIDS, respiratory cancer, breast cancer for women, suicide and traffic accidents. In addition, two determinants-alcohol abuse and tobacco abuse-for which a clear conceptual link could be established between all methods were chosen. Connections between priorities identified through the DALY and the Delphi method lead to further inclusion of chronic back pain and depression. Some issues solely identified through the Delphi survey were included as they were consistently considered important by professionals and the lay public alike-violence in the family, unemployment, social exclusion.

Conclusions-These results indicate that health priorities, and by extension health care priorities, would benefit from using a mix of quantitative and qualitative research methods. The triangulation of results allows for a broader perspective and makes results more acceptable.

(F Epidemiol Community Health 2000;54:388-393)
\end{abstract}

About 20 years ago the WHO started to encourage the definition of health priorities as an essential step in national or regional health planning. ${ }^{1}$ To date about a third of all industrialised countries have formulated, and sometimes already revised, national health priorities and targets. ${ }^{23}$ Well known examples are the United Kingdom, ${ }^{4}$ France, ${ }^{5}$ Quebec, ${ }^{6}$ Australia $^{7}$ and the USA. ${ }^{8}$ More recently, rising health care costs have brought priority setting in health care to the forefront of the public health debate..$^{9-11}$ The complexity of setting priorities for health care, leading eventually to decisions on health care rationing, has been the focus of the second international conference on health care priorities. ${ }^{12}$ However, there is not one unique method to be used to determine priorities. Premature mortality, ${ }^{13}$ indicators combining mortality and morbidity, ${ }^{14}$ potential for health gain ${ }^{15}{ }^{16}$ or cost effective health gain ${ }^{17}$ have been used to estimate the relative importance of specific conditions. In other instances, priorities have been set on the basis of general health data and documented or perceived severity of health conditions. ${ }^{18}$ In some instances, a "public" debate was held to solicit broad public consensus on health priorities. ${ }^{19}$

In Switzerland, the political system is extremely decentralised and each of the 23 cantons is responsible for developing its own health system and health policy. Geneva is one of the medium sized cantons with about 400000 inhabitants and an area of 246 square $\mathrm{km}$. Its health care system guarantees excellent care for acute and chronic conditions and is widely accessible to the population. ${ }^{20}$ However, like many industrialised regions, it has been confronted in past years with increasing health care costs and the dilemma of financing a health care system that is heavily biased towards treatment, care and cure at the expense of consistent preventive strategies and services. Despite its excellent mortality indicators ${ }^{21}$ there is mounting epidemiological evidence and a felt need to devote more attention and resources to prevention strategies. ${ }^{22}$ In this context, the Health Department of the canton of Geneva decided in 1996 to define, for the first time, a set of health priorities that should receive special attention and resources over the next 5-10 years.

None of the procedures that have been used to define health priorities was judged, on its own, to be entirely satisfactory for Geneva for several reasons. Firstly, health professionals and the public in general are very sensitive to health issues, and it would have been unacceptable to conduct a priority setting exercise without taking into consideration their views. Secondly, decisions implying reallocation of resources would need to be backed up by solid scientific data to gather broad professional, political and public consensus. Thirdly, the use of traditional mortality indicators as gold standards is problematic as mortality indicators alone cannot discriminate among conditions when mortality rates are so low. We thus used three complementary approaches including traditional mortality indicators (potential years of life lost), disability adjusted years of life lost, and a Delphi survey, to identify a set of robust priorities by triangulating results between the three methods. This paper briefly 
Table 1 Proportion (\%) of potential years of life lost (PYLL) * attributable to major causes of deatht by gender

\begin{tabular}{lcll}
\hline Total PYLL & PYLL men 16 080 & PYLL women 8142 & PYLL all 24 222 \\
\hline Causes of death & $\%$ & $\%$ & $\%$ \\
Cardiovascular diseases $¥$ & 17.7 & 13.2 & 14.9 \\
IHD & 5.0 & 4.0 & 4.7 \\
AIDS & 12.3 & 7.8 & 10.9 \\
Other violent deaths & 11.2 & 8.5 & 10.3 \\
Suicide & 8.6 & 9.0 & 8.7 \\
Respiratory cancer & 8.3 & 4.8 & 7.1 \\
Traffic accidents & 6.1 & 2.8 & 5.0 \\
Breast cancer & NA & 9.9 & 3.3 \\
Liver cirrhosis & 2.1 & 3.5 & 2.6 \\
Colon/rectal cancer & 1.7 & 2.5 & 2.0 \\
Cerebrovascular disease & 1.3 & 1.4 & 1.3 \\
\hline
\end{tabular}

*Age limit is 75 years. †Mortality statistics 1990-1994. ¥This includes the following categories: ischaemic heart disease (IHD), heart failure, ventricular arrhythmias, general arteriosclerosis and "ill defined conditions of heart disease". To allow comparison with table 2 we show the \% of PYLL attributed to ischaemic heart disease in italics. \$From falls, poisoning/overdose, other accidents (excluding traffic accidents and suicide).

Table 2 Proportion of DALYs attributed to the 15 most important health problems

\begin{tabular}{|c|c|c|c|c|}
\hline \multirow{2}{*}{\multicolumn{2}{|c|}{ Disease }} & \multirow{3}{*}{$\begin{array}{l}\text { \% of total } \\
D A L Y s \\
8.0\end{array}$} & \multicolumn{2}{|c|}{ Disability - Mortality } \\
\hline & & & \multirow{2}{*}{$\begin{array}{l}\% Y L D \\
8.6\end{array}$} & \multirow{2}{*}{$\frac{\% Y L L}{91.4}$} \\
\hline 1 & Ischaemic heart disease & & & \\
\hline 2 & Unipolar major depression & 6.9 & 100.0 & 0 \\
\hline 3 & AIDS & 4.8 & 25.4 & 74.6 \\
\hline 4 & Alcohol abuse & 4.7 & 96.6 & 3.4 \\
\hline 5 & Suicide/other self inflicted injuries & 3.8 & 8.6 & 91.4 \\
\hline 6 & Ostheoarthritis & 3.1 & 99.1 & 0.9 \\
\hline 7 & Trachea, bronchus, lung cancer & 2.9 & 7.3 & 92.7 \\
\hline 8 & Dementia + degenerative CNS & 2.8 & 97.9 & 2.1 \\
\hline 9 & Cerebrovascular disease & 2.6 & 30.1 & 69.9 \\
\hline 10 & Traffic accidents & 2.5 & 31.3 & 68.7 \\
\hline 11 & Schizophrenia & 2.1 & 100 & 0 \\
\hline 12 & Falls & 2.1 & 65.2 & 34.8 \\
\hline 13 & Breast cancer ${ }^{\star}$ & 1.9 & 13.6 & 86.4 \\
\hline 14 & Bipolar disorder & 1.7 & 100 & 0 \\
\hline 15 & Obsessive-compulsive disorders & 1.7 & 100 & 0 \\
\hline
\end{tabular}

ॠThe overall ranking of breast cancer is relatively low because of the fact that this health problem is practically restricted to women. The analysis by gender shows that breast cancer ranks fourth in women. and disability. The assumptions, data requirements, inputs and results of the worldwide study have been published between 1994 and 1997. ${ }^{29}{ }^{30}$ Since then this method has been or is being used in the Netherlands, Spain, Sweden, Australia and the USA, ${ }^{31}$ although results for those countries have not been published yet. Mortality estimates, averaged over a period of five years, were obtained from the National 1990-1994 mortality data base, the most recent mortality data available for the canton at the time of the study. Classification of health conditions, age weighting and discounting of future years were carried out according to the Global Burden of Disease (GBD) procedures. ${ }^{32-34}$ Mortality had to be recoded from ICD-8 to ICD-9. We used published estimates for Established Market Economies $(\mathrm{EME})^{35}$ to estimate Years Lived with Disability (YLD) as specific morbidity estimates on disease onset, incidence and duration are rarely available for Geneva. Detailed methods and results on the DALY analysis of this paper have been reported elsewhere. ${ }^{36}$

DELPHI SURVEY

A Delphi survey was conducted to gather the opinion of concerned groups, both as health professionals or as representatives of the general population. Since its initial development $^{37}$ the Delphi method has been widely used in health and medicine, ${ }^{38} 39$ and the procedures have been standardised. ${ }^{40}{ }^{41}$ For our study, we defined five panels, each of them representing a fairly homogenous group: all political leaders involved in decision making with regard to health and social support issues ("political"), the directors of medical and social institutions ("institutional"), a purposeful sample of medical and paramedical professionals established in private practice ("ambulatory"), and of managers of health related non-governmental organisations ("NGO"). Finally, selected leaders of community groups with no direct involvement in health ("community") were included. Overall, 293 persons were invited to participate in the survey.

On the basis of previous studies* we designed a questionnaire providing a comprehensive list of health determinants (20 items) and disease oriented problems (43 items), which was pilot tested in a small group of professionals and lay persons. The first round of the questionnaire was used to elicit the opinion of panel members on the 10 most important determinants and health problems. Respondents were asked to take into consideration the

* Three studies carried out in Geneva had examined the health status of the population and perception about health priorities: La santé des genevois. Les Cahiers de la Santé. No 1, Juin 1993. Etter JF. Rapport d'évaluation du CIPRET-Genève. IMSP, Université de Genève, 1996. La santé dans le canton de Genève, 1ère enquête Suisse sur la santé. ISP, Lausanne, 1996. General morbidity and mortality patterns for the European region were taken from: European Community atlas of avoidable deaths. 2nd ed. Vol 1. Oxford University Press, 1991. Investing in health. World Development Report 1993. Oxford University Press. In addition, a questionnaire developed for a similar Delphi study in Ile-deFrance was used. 
Table 3 Health problems and determinants by order of priority and by panel

\begin{tabular}{lllllll}
\hline Final number of respondents * & Political 25 & Institutional 40 & Ambulatory 29 & NGO 31 & Community 40 & Total 165 \\
\hline Health problems & & & & & & \\
Depression & $94(1)$ & $97(1)$ & $86(1)$ & $84(2)$ & $83(1)$ & $89(1)$ \\
Cardiovascular disease & $89(2)$ & $93(2)$ & $81(2)$ & $90(1)$ & $73(2)$ & $81(2)$ \\
AIDS & $56(8)$ & $67(4)$ & $62(6)$ & $72(3)$ & $70(3)$ & $66(3)$ \\
Breast cancer & $78(3)$ & $60(7)$ & $76(4)$ & $68(4)$ & $46(11)$ & $64(4)$ \\
Chronic back pain & $39(10)$ & $73(3)$ & $71(5)$ & $68(4)$ & $53(7)$ & $63(5)$ \\
Respiratory cancer & $78(3)$ & $63(5)$ & $62(6)$ & $56(8)$ & $53(7)$ & $61(6)$ \\
Violence in the family & $61(6)$ & $47(11)$ & $57(8)$ & $64(6)$ & $67(5)$ & $59(7)$ \\
Hypertension & $61(6)$ & $63(5)$ & $86(3)$ & $44(10)$ & $43(12)$ & $58(8)$ \\
Suicide & $50(9)$ & $53(9)$ & $38(12)$ & $60(7)$ & $70(3)$ & $56(9)$ \\
Traffic accidents & $67(5)$ & $53(9)$ & $57(8)$ & $52(9)$ & $50(9)$ & $55(10)$ \\
Health determinants & $67(2)$ & $63(2)$ & $81(1)$ & $76(1)$ & $63(2)$ & $70(1)$ \\
Alcohol abuse & $72(1)$ & $80(1)$ & $81(1)$ & $56(3)$ & $37(8)$ & $65(2)$ \\
Tobacco abuse & $39(6)$ & $50(3)$ & $57(3)$ & $56(3)$ & $67(1)$ & $55(3)$ \\
Deteriorated family environment & $61(3)$ & $43(6)$ & $48(4)$ & $64(2)$ & $57(3)$ & $52(4)$ \\
Unemployment & $55(5)$ & $50(3)$ & $48(4)$ & $40(7)$ & $57(3)$ & $50(5)$ \\
Social exclusion & & &
\end{tabular}

*This indicates the final number of respondents after the second round. Overall, $56 \%$ of panel members participated in the first round, and $79 \%$ of these in the second round. The first figure in each box reflects the actual percentage of panel members who have listed a given item as a priority in a set of 10 . The figure in parentheses indicates the actual ranking of this item within the list of 10 .

frequency and severity of a problem, its socioeconomic impact and the possible effectiveness of interventions in making their choice, and to recommend actions to be undertaken to improve the situation in the identified priority areas. The questionnaire for the second round listed 12 determinants and 18 health problems that had been chosen by at least $30 \%$ of participants in the first round. In the second round, panel members were asked to choose five determinants and 10 problems, indicating their priorities, and to give a priority score to each recommended intervention. Because of a high convergence of opinion after the first two rounds, a third round was not necessary. ${ }^{42}$ More detailed methods and results have been published elsewhere. ${ }^{43}$

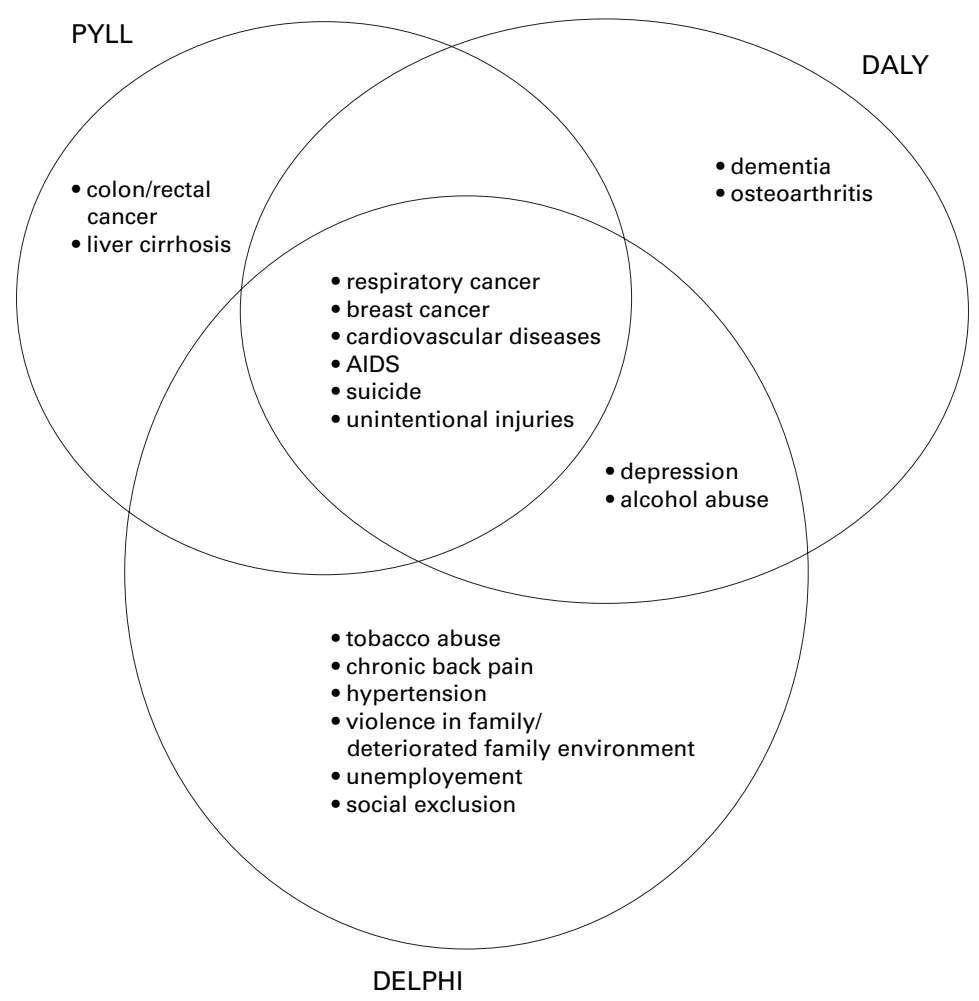

Figure 1 Overlap in health priorities identified through each method.

\section{Results}

Table 1 shows the 10 most important disease categories ranked according to their share of total PYLLs in the canton. Cardiovascular diseases appear as the top priority health problem for men and women in Geneva, followed by breast cancer for women and AIDS for men. Overall violent deaths including traffic accidents, other accidents and suicide accumulate a high proportion of premature deaths (24\%).

Table 2 presents the list of the 15 most important health problems ranked by their contribution to total DALYs per year in the canton, and shows the relative importance of mortality (YLL) and morbidity (YLD). Ischaemic heart disease appears as the single most important priority, followed by unipolar major depression, AIDS, and alcohol abuse. Neuropsychiatric disorders appear in six of the 15 priority problems, accounting for $20.9 \%$ of DALYs. HIV/AIDS is the third contributor to DALYs in Geneva. Suicide and other self inflicted injuries account for more DALYs than road traffic accidents and falls. Breast cancer ranks fourth in women (13th position in overall ranking). Respiratory cancer ranks seventh.

Table 3 shows the 10 health problems and five determinants chosen as priority issues by the five Delphi panels, and the summary results from all panels. Depression and cardiovascular disease rank as the top two priority issues. AIDS appears again as the third issue, and breast cancer as the fourth. A high rank was given to "violence in the family" presented, overall, as the fifth priority issue. Some interesting differences emerge between panels with regard to AIDS (rated as a high priority by community leaders but given a lower priority ranking by politicians), breast cancer, and hypertension (rated relatively low by the community and NGO panel, whereas it is given high priority by the two "medical" panels). Alcohol and tobacco abuse are seen as the most important health determinants to be tackled, with the notable exception of the community group who ranks tobacco abuse comparatively low. With regard to the interventions proposed for each priority, they mainly relate to primary and secondary prevention and include a range 
Table 4 Health problems by order of priority according to the method: Potential Years of Life Lost (PYLL), Disability Adjusted Life Year (DALY) or the opinion of health professionals and the lay public (Delphi)

\begin{tabular}{|c|c|c|c|}
\hline$P Y L L$ & $D A L Y$ & Delphi study & Final choice \\
\hline $\begin{array}{l}\text { cardiovascular diseases }{ }^{\star} \\
\text { AIDS } \\
\text { other violent deaths } \\
\text { suicide } \\
\text { respiratory cancert } \\
\text { traffic accidents } \\
\text { breast cancer } \\
\text { liver cirrhosis } \\
\text { colon/rectal cancer } \\
\text { cerebrovascular disease }\end{array}$ & $\begin{array}{l}\text { IHD } \\
\text { depression } \\
\text { AIDS } \\
\text { alcohol abuse } \\
\text { suicide } \\
\text { ostheoarthritis } \\
\text { respiratory cancer } \\
\text { dementia } \\
\text { cerebrovascular disease } \\
\text { traffic accidents }\end{array}$ & $\begin{array}{l}\text { depression } \\
\text { cardiovascular diseases } \\
\text { AIDS } \\
\text { breast cancer } \\
\text { chronic back pain } \\
\text { respiratory cancer } \\
\text { violence in the family } \\
\text { hypertension } \\
\text { suicide } \\
\text { traffic accidents } \\
\text { Determinants } \\
\text { alcohol abuse } \\
\text { tobacco abuse } \\
\text { deteriorated family environment } \\
\text { unemployement } \\
\text { social exclusion }\end{array}$ & $\begin{array}{l}\text { depression } \\
\text { cardiovascular diseases } \\
\text { AIDS } \\
\text { breast cancer } \\
\text { chronic back pain } \\
\text { violence in the family } \\
\text { suicide } \\
\text { unintentional injuries } \ddagger \\
\text { alcohol abuse } \\
\text { tobacco abuse } \\
\text { unemployement } \\
\text { social exclusion }\end{array}$ \\
\hline
\end{tabular}

${ }^{\star}$ Excluding cerebrovascular disease. †Including larynx, bronchus and lung cancer. $¥$ Including traffic accidents, domestic accidents, falls, etc.

of legal, social, environmental and medical measures.

Several health conditions are unanimously selected by all three methods as top priorities: cardiovascular diseases, AIDS, respiratory cancer, breast cancer, suicide and unintentional injuries including traffic accidents (fig 1). Alcohol abuse, given priority by the DALY and Delphi method, can be closely linked to liver cirrhosis in the PYLL analysis. Similarly tobacco abuse, identified as an important health determinant through the Delphi survey is closely linked to respiratory cancer. The DALY analysis and Delphi study coincide in the identification of unipolar major depression as a high priority, while it is entirely missing in the PYLL analysis. Two health problems that appear solely in the Delphi study-chronic back pain and hypertension-can be linked to results of the DALY analysis. Hypertension leads to cardiovascular and cerebrovascular diseases, and chronic back pain may have some relation with osteoarthritis.

Finally, the Delphi survey adds several elements that would have been missed by the two quantitative methods. Violence in the family has been given high priority by all panels. The importance given by participants in the Delphi survey to this issue was further corroborated by the high ranking of a deteriorated family environment in choosing priority health determinants. Although social determinants such as a deteriorated family environment, unemployment and social exclusion, are not directly identifiable through the two quantitative methods, they may be linked with the broader category of mental disorders.

\section{Discussion}

The final choice of health priorities (table 4) for the Canton of Geneva was guided by a three step approach.

(1) All six health problems unanimously identified by the three methods plus those two for which a clear conceptual link could be established between the three methods (alcohol and tobacco abuse) were chosen. By doing so we incorporated cardiovascular diseases, AIDS, breast cancer, suicide, unintentional injuries (traffic accidents, falls, other acci- dents), alcohol abuse and tobacco abuse. However, respiratory cancer was not included in the final list considering it more a consequence of tobacco abuse than a prime priority. In fact, all interventions proposed by the respondents in the Delphi survey to improve the situation with regard to respiratory cancer were linked to tobacco abuse.

(2) Clear links between priorities identified through the DALY and the Delphi method lead to further inclusion of chronic back pain, instead of osteoarthritis, and depression. These decisions were supported by data currently available for the canton of Geneva. In 1993, $9.4 \%$ of women and $5.6 \%$ of men reported a medically diagnosed depression during a population-based survey. This was considerably higher than the Swiss average $(5.4 \%$ and $2.5 \%$ respectively). ${ }^{44}$ In addition, $36 \%$ of women and $31 \%$ of men considered themselves to be in bad mental health. In the same survey a quarter of the respondents said they had suffered from joint problems or acute back pain in the preceding month. In addition, bone and joint disease (mainly back problems) are the main cause for attributing an invalidity pension to men.

(3) Finally, the three main social determinants solely identified through the Delphi survey (violence in the family, unemployment, social exclusion) were included as they were consistently considered important by professionals and the lay public alike. Regarding violence in the family, data on physical abuse of children, including sexual abuse, are still very patchy. We know, however, that physical abuse of children is pervasive in Switzerland, ${ }^{45}$ and that a third of school aged girls and $10 \%$ of boys in Geneva have suffered from some type of sexual abuse. ${ }^{46}$ The first study on domestic violence against women was carried out in Switzerland in 1996, showing that during their life time $20 \%$ of women had been physically and $40 \%$ psychologically abused by their partner(s) ${ }^{47}$ Having included violence in the family as a priority, we discarded a "deteriorated family environment" in the list of determinants. Unemployment and social exclusion were both considered important though broad and "indirect" health determinants. 
Participants in the survey had pointed to the frequency and recent increase of these phenomena and their important impact on health, often referring to a vicious cycle, including several of the determinants (that is, unemployment can lead to a deteriorated family environment, to additional stress, to alcohol abuse and social exclusion). In fact, the unemployment rate has tripled in Geneva since the beginning of the 1990s and in particular, long term unemployment (more than one year) has increased 20 -fold. Some local studies have shown the severe impact of unemployment on health status. ${ }^{48} 49$

Moving from the results of the PYLL analysis to those of the DALY study to those of the Delphi survey, we found convergence on certain priorities, and that each subsequent method also broadens and enriches the argument. Obviously the concept inherent in each method "drives" the result. The limitations of the premature mortality analysis in setting priorities in low mortality populations stems from the fact that it excludes all non-fatal consequences of acute and chronic conditions and that deaths occurring after age 75 are not considered a loss. The DALY method circumvents these problems, but in turn is unable to identify psychosocial and socioeconomic health conditions and determinants perceived by the population as important issues. The Delphi method provides the broadest view on health, but may be dependent on the selection, responsiveness and quality of the participants. Two advantages of this method are that it portrays the perceived importance of health problems and their determinants, and that it allows to elicit opinions on the most effective interventions to tackle them. It thus takes into account social preferences and points to actions that are seen as feasible and acceptable.

The main limitation of this approach is that each method uses by design a different classification of health problems thus leading to a certain subjectivity in the comparison of results and the final choice. However, based on our findings, we believe that health priorities, and by extension health care priorities, may benefit from using a mix of quantitative and qualitative research methods. Qualitative results alone, however valuable, would most probably not be agreeable if they were not supported by epidemiological data and analyses, such as the burden of disease. The triangulation of results allows for a broader perspective, makes the final choice socially more acceptable and improves consensus on the choice of priorities. This may be particularly important as the priorities selected for the canton of Geneva incorporate broader social issues that have traditionally been left out when setting health priorities. As demonstrated by the responses to the Delphi survey resolving these problems will require inter-sectoral collaboration rather than relying on health care services as the unique response, thus implying a strong commitment of all parties concerned.
KEY POINTS

- Health priorities, and by extension health care priorities, may be best determined by using a mix of quantitative and qualitative research methods.

- In this study the combination of a premature mortality analysis, an assessment of disability adjusted life years and an opinion survey was chosen.

- This led to incorporating broader social issues that have traditionally been left out when setting health priorities.

- The triangulation of results allows for a broader perspective, makes the final choice socially more acceptable and improves consensus on the selected priorities.

The study was carried out in 1997 as part of a mandate given by the Health department of the canton of Geneva to the Institute for social and preventive medicine.

Funding: the study was totally funded by the Health department of the canton of Geneva within a mandate given to the Institute of social and preventive medicine.

Conflicts of interest: none.

1 World Health Organisation. Targets for Health for All. Copenhagen: WHO, Regional Office for Europe, Copenhagen, 1985 .

2 Kickbusch I. Targets for health: experiences and directions. InterKickbusch I. Targets for health: experiences and directions. Inter-
national workshop on target setting, Brussels, March 1996. Bielefeld: European Public Health Centre, NRW,

3 Nutbeam D, Wise M. Planning for health for all: international experience in setting goals and targets. Health Promotion Int 1996;11:219-26.

4 The Health of the Nation: a strategy for health in England, Presented to Parliament by the Secretary of State for Health by command of her Majesty, Fuly 1992. London: HSMO, 1992.

5 France. Ministère des affaires sociales de la santé et de la ville, Haut Comité de la Santé Publique. La Santé en France: rapport général. Paris: La Documentation française, 1994.

6 La politique de la santé et du bien-être. Quebec: Gouvernement du Québec, Ministère de la Santé et des Services sociaux, 1992.

7 Better health outcomes for Australians: National goals, targets and strategies for better health outcomes into the next century. Canberra: Commonwealth Department of Human Services and Health, Commonwealth of Australia, 1994.

8 Healthy People 2000: midcourse review and 1995 revisions. Healthy People 2000: midcourse review and 1995 revisions.
Washington: US Department of Health and Human Services, Public Health Service, 1995

9 Ham C. Priority setting in the NHS: reports from six districts. BMF 1993;307:435-8

10 Hadorn DC, Holmes AC. The New Zealand priority criteria project. Part 1: Overview. BMF 1997;314:131-4.

11 Dixon J, New B. Setting priorities New Zealand style. BMf 1997;314:86-7.

12 Holm S. Goodbye to the simple solutions: the second phase of priority setting in health care. BMF 1998;317:1000-7.

13 Centers for Disease Control. Premature mortality in the United States: public health issues in the use of years of potential life lost. MMWR 1986;35:1-11S.

14 Colvez A, Blanchet M. Potential gains in life expectancy free of disbility: a tool for health planning. Int $\mathcal{F}$ Epidemiol 1983; 12:224-9.

15 Robison R. Cost-utility analysis. BMF 1993;307:859-62

15 Robison R. Cost-utility analysis. BMF 1993;307:859-62. Med 1992;34:559-69.
Med

17 Hadorn D.C. Setting health care priorities in Oregon. fAMA 1991;266:2135-141.

18 Smith A, Jacobson B, eds. The Nation's Health: a strategy for the 1990s: a report from an independent multidisciplinary committee. London: King Edward's Hospital Fund for London, 1990.

19 Priorités nationales de santé publique 1997-2002. Quebec: Gouvernement du Québec, Ministère de la Santé et des Services sociaux, 1997.

20 Gilliand P, Erismann M, coord. Le rapport Gilliand sur le système de santé genevois. Les cahiers de la santé no 7. Genève: Direction de la santé publique, 1996

21 OCSTAT, Etudes et documents No 24. La santé en chiffres: recueil de statistiques socio-sanitaires sur le canton de Genève. Geneva: Office Cantonal de la Statistique, 1998.

22 Schopper D, Ammon C, Rougemont A. Planification qualitative du système de santé genevois: les domaines d'actions prioritiaires et la réforme du système de santé. Les cahiers de la santé No 9.1. Geneva: Département de l'action sociale et de santé No 9.1 . Ganté, 1998. 
23 Demsey $M$. Decline in tuberculosis. The death rate fails to tell the entire story. Am Rev Tuberculosis 1947;56:157-64

24 Haenszel W. A standardized rate for mortality defined in units of lost years of life. Am F Public Health 1950;40:17-26.

25 Romeder JM, McWhinney JR. Potential years of live lost between ages 1 and 70: an indicator of premature mortality for health planning. Int $\mathcal{F}$ Epidemiol 1977;6:143-51.

26 Gadner J W, Sanborn J S. Years of potential life lost (YPLL)What does it measure? Epidemiology 1990;1:322-9.

27 Murray CJL, Lopez A. Quantifying disability: data, methods and results. Bull WHO 1994;72:481-94.

28 World Bank. World development report 1993: investing in health. New York: Oxford University Press, 1993.

29 Murray CJL, Lopez AD, Jamison DT. The global burden of disease in 1990: summary results, sensitivity analysis and future directions. Bull WHO 1994;72:495-509.

30 Murray CJL, Lopez AD. Global mortality, disability, and the contribution of risk factors: Global Burden of Disease contribution of risk factors: Gl
Study. Lancet 1997;349:1436-42.

31 Murray CJL, Lopez AD. The utility of DALYs for public health policy and research: a reply. Bull WHO 1997;75: health polic

32 Murray CJL, Lopez A.The incremental effect of ageweighting on YYLs, YLDs, and DALYs: a response. Bull WHO 1996;74:445-6.

33 Murray CJL, Acharya AK. Understanding DALYs. fournal of Health Economics 1997;16:703-30.

34 Murray CJL, Lopez A. The global burden of disease. Boston Harvard University Press, 1996.

35 Murray CJL, Lopez A. Global health statistics. Boston: Harvard University Press, 1996.

36 Schopper D, Pereira J, Torres A, et al. Estimating the burden of disease in one Swiss canton: what can DALYs tell us? Int 7 Epidemiol (in press)

37 Dalkey NC. The Delphi method: an experimental study of group opinion. RM-5888-PR. Santa Monica: Rand Corp, 1969.

38 Moscovice I, Armstrong P, Shortell S, et al. Health services research for decision-makers: the use of the Delphi technique to determine health priorities. $\mathcal{f}$ Health Polit Policy Law 1977;2:388-410.

39 Bettcher DW, Sapirie S, Goon EHT. Essential public health functions: results of the international Delphi study. World Health Stat Q 1998;51:44-54.

40 Delbecq AL, van de Ven AH, Gustafson PH. Group technique for programme planning. A guide to nominal group and Delphi processes. Glenview, IL: Scott, Foresman and Company, 1975.

41 Listone HA, Murray T. The Delphi method, technics and applications. Massachussetts: Addison-Wesley, 1975.

42 Fink A, Kosecoff J, Chassin M, et al. Consensus methods: Characteristics and guidelines for use. A f Public Health 1984;74:979-83.

43 Schopper D, Ammon C, Ronchi A, et al. When providers and users define health priorities: the results of a Delphi survey in the canton of Geneva. Soc Sci Med (in press).

44 Weiss W, Zimmermann E, Kiefer A, eds. La santé dans le canton de Genève: projet GCI/Coopération intercantonale en matière d'analyse des données issues de la lère enquête suisse sur la santé. Lausanne: ISP, 1996.

45 Groupe de travail "Enfance maltraitée". Enfance maltraitée en Suisse: rapport final présenté au chef du Département fédéral de l'intérieur. Berne: Office central des imprimés et du matériel, 1992 .

46 Halperin D, Bouvier, Rey Wicky H . A contre-coeur, à contrecorps. Regards pluriels sur les abus sexuels d'enfants. Geneva: Medecine et Hygiene, 1997

47 Gillioz L, De Puy J, Ducret V. Domination et violence contre la femme dans le couple. Lausanne: Payot, 1997.

48 Frigul N, Bretin H, Metenier I, et al. Atteintes à la santé et exclusion professionnelle: une enquête auprès de 86 femmes en chômage de longue durée. Travail et Emploi 1993;56:34-44.

49 Meystre-Agustoni G. Chômage et santé: analyse de la littérature. Lausanne: Institut universitaire de médecine sociale et préventive, 1997. 